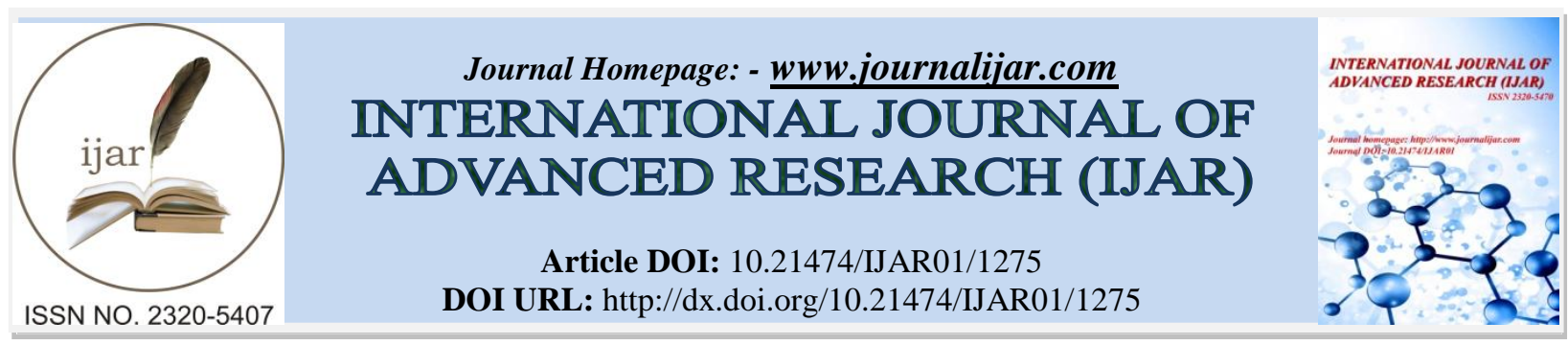

RESEARCH ARTICLE

\title{
EVALUATION OF QUESTIONNAIRE AS A RELIABLE RESEARCH INSTRUMENT IN LIBRARY AND INFORMATION SCIENCE: CASE STUDY OF THE LIBRARY STAFF, FEDERAL UNIVERSITY OF TECHNOLOGY, OWERRI, NIGERIA.
}

\section{DR. (MRS) UMUNNAKWE ${ }^{1}$, G. C, IROEZE PAULINE ${ }^{2}$ and EZE JACINTHA U (Ph.D) ${ }^{3,4}$.}

1. Senior librarian, Co-Ordinator Acquisition Unit, Federal University Of Technology, Owerri, Had B.ed Library and Information Science From Abia State University Uturu, MLS From Imo state University, Owerri and Ph.d From, University Of Nigeria, Nsukka.

2. Assistant Librarian, Processing Unit, Federal University Of Technology, Owerri, Had B.ed Library and Information Science From Calabar (Unical) MLS from Absu and Ph.d in view.

3. Ph.d, CLN, Lecturer, Enugu State University Of Science And Technology, Agbani, Enugu, Nigeria.

4. Part Time Lecturer, College Of Education Technical, Enugu (Affiliated To Nnamdi Azikiwe University, Awka. A Chartered Librarian, A Reviewer and an Editor in some Reputable local and International Journals.

\section{Manuscript Info}

Manuscript History

Received: 18 June 2016

Final Accepted: 19 July 2016

Published: August 2016

Key words:-

Questionnaire, Data collection, Library and Information Science, Research, Nigeria.

\begin{abstract}
Considering the increasing number of questionnaire usually submitted to research, training and statistics Unit of FUTO Library by researchers in the field of library and information science, the researchers was agitated and motivated to find out the reliability of the questionnaire as an instrument for data collection in this discipline. Being a case study, the target population was the FUTO Library Senior Staff made up of academic and non academic staff. Questionnaires were used to collect data from 96 senior staff who were the respondents. These were chosen due to the fact that they have been involved in a number of researches to get to their level in the library. Data was analyzed using frequency counts and percentages and presented in tables for clarity. The result showed that the researchers, despite the lapses of the questionnaire strongly relied more on the questionnaire than other instruments for data collection in most of their researches.
\end{abstract}

Copy Right, IJAR, 2013,. All rights reserved.

\section{Introduction:-}

Research is an important component of any discipline which is critical to the growth and development of any profession. It provides and produces knowledge which is needed for understanding and combined with skills to lead to effective action. Research has been defined by different people in different forms. Leedey (1993) defines research as "the manner in which to solve problems in a systematic way to push back the frontiers of human ignorance or to confirm the validity of the solutions to problem which have presumably been solved." In another view, Best and Kahu (1998) saw it as the systematic and objective analysis and records of controlled observation that may lead to the development of generalization, principles, theories, resulting in prediction and ultimate control of many events that may be consequences or causes of specific activities. Aina (2002) listed the following as characteristics of research; usually a piece of research work begins with a problem in mind which the researchers set to solve. Research is expected to lead to the development of generalization of principles and theories that can be applied to

Corresponding Author:- EZE JACINTHA U.

Address:- Ph.d, Cln, Lecturer, Enugu State University Of Science And Technology, Agbani, Enugu, 788 Nigeria. 
similar situations. Research is based on personal experience or empirical data and involves gathering of data. It is essential to have procedures that must be carefully designed and the search requires the researcher to have expertise in the area of research. It is also important that a researcher should be objective, logical, honest, courageous and patient. Completed research must be accurately reported and disseminated and a research study is expected to contribute something new to knowledge. Furthermore, Osuala (2005) saw research as the process of arriving at dependable solutions to problems through the planned and systematic collection, analysis and interpretation of data. It is most important to look for enabling man to relate more effectively to his environment to accomplish his purpose and to solve his conflicts. He listed the problems of research as illiteracy, secrecy, scanty statistics etc.

Data collection is an indispensable prerequisite for the actualization of any purposeful research. Data can be seen as the facts and figures collected during the course of the research work which can be articulated, analyzed and interpreted to arrive at a dependable result. Data collection is the pivot around which every research or project revolves. Data collection according to Obodoeze (1996) refers to obtaining relevant information regarding the major ideas of the hypothesis of the study for the purpose of demonstrating whether or not they are true. Without data whether primary or secondary, the research work cannot be complete. To Onyango (2002) data collection involves measuring some research phenomenon, whether it is a process, an object or human subject behaviour. Measurement of these objectives differs from one research project to another, depending on the purpose of the enquiry and the availability of suitable instruments.

A good research utilizes valid and reliable data gathering procedures, instruments and techniques. In order to carry out a good research therefore, data with which to test the hypothesis or answer the questions should be provided (Best and Kahn1998). This led the interest of the researchers to go towards the instrument for data collection hence the importance of well gathered data in research cannot be neglected.

\section{Data collection instruments:-}

Some popular instruments for data collection used in research include questionnaires, interviews, observational techniques, self report instrument, documentary sources, focus group discussion etc. For the purpose of this paper, only the questionnaires as a tool for data collection will be studied since it is very much used by researchers in library and information science, social sciences and humanities. The questionnaire by definition is simply a form composed to present statements or questions about some attributes or relationships and provision for the respondent to write his reactions to each statement or question (Nkwocha, 2007). This entails that a questionnaire must be articulated, written and distributed from which the responses can be gathered. A questionnaire is a set of systematically structured questions used by a researcher to get needed information from respondents. They are according to Brown (2001) any written instruments that present respondents with a series of questions or statements to which they are to react either by writing out their answers or selecting from among existing answers. In the words of Key (1997) a questionnaire is a means of eliciting the feelings, beliefs, experiences, perceptions, or attitudes of some sample of individuals. The questionnaire is most frequently a very concise, preplanned set of questions designed to yield specific information to meet a particular need for research information about a pertinent topic.

It consists of a set of questions for submission to a number of persons or respondents in order to gather data. Questionnaires are flexible and can be used in the collection of different types of data especially subjective verses objective data as well as quantitative and qualitative data. The questionnaire can mostly be useful and used when resources and money are limited; when it is necessary to protect the privacy of the participants and when corroborating other findings where factual information is desired. Questionnaires when distributed by the researcher usually make the researcher have limited control over the environment, which entails that the validity of the result relies on the honesty of the respondents.

The questionnaire may be self administered, posted or presented in an interview format. As Oppenheim (1992) put it, a questionnaire may include check lists, attitude scales, projective techniques, rating scales and a variety of other research methods. As an important research instrument and a tool for data collection, a questionnaire has its main function of measurement. It is the main data collection method used in surveys and yields quantitative data. The validity of questionnaires relies first and foremost on reliability. If a questionnaire cannot be seen to be reliable; there is no discussion of validity.

The validity and reliability of a questionnaire is very important for accurate and reliable results. The questionnaires must be finalized and vetted when the first draft is made before a pre-test. A face validation approach is the most 
appropriate to this because it helps in modeling the questionnaire in line with the required investigation, enhance adequate coverage for the topic of study and collection of factual data. An expert opinion is therefore needed on any questionnaire to be used for a research work. This according to Onyango (2002) will help to identify methodology weaknesses in the instrument, such as faculty scales; face validity of the questions such as whether they make sense, are easy to understand, are probing in nature etc. A pre-test of the questionnaires can be effective and be done with these validity and reliability tests to certify the questionnaires as being viable and reliable. Pre-test permits a preliminary testing of the hypothesis, point out a variety of unanticipated problems relating to design methodology in addition to other related issues to do with getting meaningful results.

Questions asked in a questionnaire can be in different forms but the commonly used ones are open (unstructured) and closed (structured) questions. Open questions are those that afford the respondent an opportunity to speak his mind. It is more detailed with little or no interviewer bias. Open response may allow graphic examples, illustrative quotes, and generally provide some unanticipated data. We may fall short of imagination in the range of possible response categories thus the strength of open-ended questions. However, analysis of this data may be difficult as varied responses would have been presented. Dornyei (2007) clearly posited that it is not advisable to have openended questions in a professional questionnaire. Closed questions are easier to answer process and analyze. They are mostly 'yes' or 'no' answers, without provision for the respondent giving his explanation (Oppenheim, 1992).The open questions enable the respondent to give a more adequate presentation of his particular case. They posses greater flexibility which may or may not be desirable but allows the respondent more leeway in certain positions which may be equivalent to saying that it allows for greater validity. It can equally increase the risk of misinterpretation (Osuala, 2005). The closed questions on the other hand permit easier tabulation and interpretation by the researcher, they essentially allow for possible answers that will be provided. On the contrary, the closed questionnaire most times provides for the respondent who does not have an answer with an alternative that can check whether it applies significantly in his case or not. The questionnaires whether open or closed according to the High Education Academy (2010) must consider these points; clarity, leading questions, phrasing, embracing, embarrassing questions, hypothetical questions, prestige, bias etc.

Onyango (2002) notes that apart from the open and closed questions, the following questions could be asked.

* Factual questions used to ascertain such things as the respondent's age, gender, marital status, educational qualification etc. This constitutes the most straight forward type of questionnaire items.

* Opinion and attitude type questions intended to determine ideas, inclinations, prejudices, convictions held etc.

* Informative questions designed to measure the respondent's knowledge about some topic.

* Self perception questions similar to attitude test questions but are restricted to one's opinions about oneself.

* Standards-of-actions question used to determine how respondents would act in certain circumstances such as a change in the seating arrangement of a local library.

* Questions about past or present behaviour.

* Projective questions that will allow respondents to answer indirectly by imposing their personal beliefs, attitudes on others. Procedures can also be utilized on eliciting opinions and attitude from respondents and these include according to Onyango; Thurston techniques, Linkert method and semantic differential.

The questionnaire as a reliable research instrument for data collection have for years been used for data collection. This has helped researchers in the collection of their research data, analyzing the data and computing their results. Mention have earlier been made on the reliability of the questionnaire which entails the appropriate measures to be taken to see that the questionnaire is well constructed, pre-tested, administered and utilized to get effective results. This then leads to the advantages of using the questionnaire. The questionnaire as a reliable tool for data collection has the following advantages as was specified by the Higher Education Academy (2010).

$>$ They permit respondents time to consider their response carefully without interference from the examples (an interviewer).

$>$ It reduces cost because it is possible to provide questions to large number of people simultaneously.

$>$ Uniformity - each respondent receives the identical set of questionnaire with close-form questions.

$>$ Responses are standardized which can assist in interpreting from large number of respondents.

$>$ Can address a large number of issues and questions of concern and is a relatively efficient way with the possibility of a high response rate.

$>$ Often, questionnaires are designed so that answers to questions are scored and scores summed to obtain an overall measure of the attitude and opinions of respondents.

$>$ They may be mailed to respondents (although this approach may lower the response rate). 
$>$ They permit anonymity: It is usually argued that anonymity increases the rate of responses and may increase the likelihood that responses reflect genuine information.

These according to Higher Education Academy are some of the advantages of questionnaire that made it to be seen as a reliable instrument for data collection. The questionnaire in as much as it is a unique data collection instrument cannot be all encompassing but have the following disadvantages as noted by the Higher Education Academy.

$\checkmark \quad$ It may be difficult to obtain a good response rate; often there is no strong motivation for respondents to respond. It is sometimes a complex instrument and if badly designed can be misleading.

$\checkmark$ The questionnaire is usually an unstable method of evaluation if probing is required; there is usually no real possibility for follow-up on answers.

$\checkmark$ Quality of data is probably not as high with alternative methods of data collection, such as personal interview.

$\checkmark \quad$ They can be misused - a mistake to try to read too much into questionnaire results. Although questionnaires have been extensively utilized as instruments for data collection, a research can be conducted on it with a view to establishing its reliability.

Key (1997) rightly pointed out the characteristics of a good questionnaire. These include -:

* Deals with a significant topic; a topic the respondent will recognize as important enough to justify spending his time in completing. The significance should be clearly stated on the questionnaire or in the accompanying letter.

* Seeks only that information which cannot be obtained from other sources such as census data.

* As short as possible, only long enough to get the essential data. Long questionnaires frequently find their way into wastebaskets.

* Attractive in appearance, neatly arranged, and clearly duplicated or printed.

* Directions are clear and complete, important terms are defined, each question deals with a single idea, all questions are worded as simply and clearly as possible, and the categories provide an opportunity for easy, accurate, and unambiguous responses.

* Questions are objective, with no leading suggestions to the desired response.

* Questions are presented in good psychological order, proceeding from general to more specific responses. This order helps the respondent to organize his own thinking, so that his answers are logical and objective. It may be wise to present questions that create a favorable attitude before proceeding to those that may be a bit delicate or intimate. If possible, annoying or embarrassing questions should be avoided.

* Easy to tabulate and interpret. It is advisable to pre-construct a tabulation sheet, anticipating how the data will be tabulated and interpreted, before the final form of the question is decided upon. Working backward from a visualization of the final analysis of data is an important step in avoiding ambiguity in questionnaire form. If mechanical tabulating equipment is to be used, it is important to allow code numbers for all possible responses to permit easy transfer to machine-tabulation cards.

Considering the fact that the questionnaire is one of the most frequently used instrument for data collection in researches across disciplines including library and information science, little has been studied and written about utilization and relevance of using questionnaires for data collection. Moreover, in library and information science researches, this has even made for scanty literature about questionnaires and their utilization in research. So a study like this one in question is called for to x-ray the details about questionnaire as an instrument for data collection and how far it is being utilized by library and information science researchers especially in Nigeria using FUTO academic library.

\section{Objectives of the study:-}

This study is intended to delve into the utilization of questionnaire as an instrument for data collection in researches in the field of Library and Information science. The study specifically intends to

1. Find out types of questions asked by researchers in the questionnaires.

2. Find out the factors considered in the construction and use of questionnaires for data collection.

3. Find out the general opinion on the questionnaire as an instrument for data collection in LIS researches.

4. Find out the general constraints to research and publishing.

\section{Methodology:-}

Descriptive survey method was adopted for the study. The instrument used for the study was the questionnaire which was administered on the senior library staff of the Federal University of Technology, Owerri. The population 
of the University Library Staff is 116 but only 96 senior staff which comprised of 30 academic staff and 66 senior non-academic staff were sampled. The group was chosen to be the population because they are likely to have been involved in researches more than their junior counterparts. Questionnaires were administered to the respondents by the researchers and adequate time allowed for the response. Data from the completed questionnaires was analyzed using frequency counts and percentages for clarity and better understanding.

Analysis of data:-

Table 1:- Background information of respondents (Biodata)

\begin{tabular}{|c|c|c|c|}
\hline 1 & Gender & Frequency & Percentage \\
\hline a. & Male & 23 & $24 \%$ \\
\hline \multirow[t]{2}{*}{ b. } & Female & 73 & $76 \%$ \\
\hline & Total & 96 & $100 \%$ \\
\hline 2. & Nomenclature & Frequency & Percentage \\
\hline a. & Academic & 30 & $31 \%$ \\
\hline \multirow[t]{2}{*}{ b. } & Non academic & 66 & $69 \%$ \\
\hline & Total & 96 & $100 \%$ \\
\hline 3. & Educational qualification & Frequency & Percentage \\
\hline a. & Ph.D & 3 & $3 \%$ \\
\hline $\mathrm{b}$. & Masters/MLS & 30 & $31 \%$ \\
\hline c. & $\mathrm{BSC} / \mathrm{BA}$ & 26 & $27 \%$ \\
\hline d. & HND & 27 & $28 \%$ \\
\hline \multirow[t]{2}{*}{ e. } & OND, Diploma/WASC & 10 & $11 \%$ \\
\hline & Total & 96 & $100 \%$ \\
\hline 4 & Years of working experience & Frequency & Percentage \\
\hline a. & $0-3$ years & 7 & $7 \%$ \\
\hline $\mathrm{b}$. & $4-7$ years & 14 & $15 \%$ \\
\hline c. & $8-11$ years & 20 & $21 \%$ \\
\hline $\mathrm{d}$. & $12-15$ years & 40 & $41 \%$ \\
\hline \multirow[t]{2}{*}{ e. } & 16 and above & 15 & $16 \%$ \\
\hline & Total & 96 & $100 \%$ \\
\hline
\end{tabular}

Table 1 presents the background information of respondents on gender, academic status, qualification and years of working experience. Data collected shows that $73(76 \%)$ were female while $23(24 \%)$ were male. The total number of senior staff were 96, 30(31\%) were academic while 66(69\%) were non academic senior staff. The staff have improved in their academic status which shows that 3(3\%) had $\mathrm{PhD}, 30(3 \%)$ had Masters/MLS; 26(27\%) BLS/BA (Bachelor's Degree) 27(28\%) had HND (Higher National Diploma) while 10(11\%) had OND/Diploma/WASC in library and information science and different fields. At present, 16 of the staff have registered for their Ph.D programmes in different universities, and 12 for their masters while others are trying to update their status by engaging in one programme or the other.

On their years of working experience, 12 - 15 years were highest with 40(41\%), 8-11 years 20(21\%), 16 and above 15(16\%), 4-7 years 14(15\%) and o-3 years had 7(7\%). In paper publication, 56(58\%) out of the 96 senior staff (both academic and non academic) the respondents indicated that they have not published papers but were engaged in research works to enhance their academic qualifications while 40(42\%) accepted having published articles in different journals in their disciplines for their professional growth and promotions. These respondents indicated that the questionnaire is a major source of their data collection, though they use other techniques like personal observation, self-report instrument, interview and documentary sources. 
Table 2:- Types of questions asked by researchers in the questionnaires.

\begin{tabular}{|l|l|l|l|}
\hline & Items & Frequency & Percentage \\
\hline 1. & Factual questions & 25 & $26 \%$ \\
\hline 2. & Opinion and attitude-related questions & 34 & $35 \%$ \\
\hline 3. & Informative question & 15 & $16 \%$ \\
\hline 4. & Self perception question & 9 & $10 \%$ \\
\hline 5. & Questions on past and present & 3 & $3 \%$ \\
\hline 6. & Standard-of-action questions & 5 & $5 \%$ \\
\hline 7 & Prospective query & 5 & $5 \%$ \\
\hline & Total & $\mathbf{9 6}$ & $\mathbf{1 0 0 \%}$ \\
\hline
\end{tabular}

The respondents had different opinions on the type of questions they asked, ranging from those who usually asked opinion and attitude-test type of question rating highest with $34(35 \%)$ to factual questions with $25(26 \%)$ and the least; questions on past and present issues with $3(3 \%)$ response rate. Informative question were also asked as indicated by $15(16 \%)$ of the respondents; questions on self perception, standard-of-action questions, and other prospective queries as indicated by $9(10 \%), 5(5 \%)$ and $5(5 \%)$ of the respondents respectively.

Table 3:- The preferred questionnaire format used by the researchers.

\begin{tabular}{|l|l|l|l|}
\hline & \multicolumn{1}{|c|}{ Items } & Frequency & Percentage \\
\hline 1. & Structured questionnaire with close-ended questions & $\mathbf{7 0}$ & $\mathbf{7 3 \%}$ \\
\hline $\mathbf{2 .}$ & Unstructured questionnaires with open-ended questions & $\mathbf{2 6}$ & $\mathbf{2 7 \%}$ \\
\hline
\end{tabular}

Table 3:- Factors considered in construction and use of questionnaires for data collection.

\begin{tabular}{|l|l|l|l|}
\hline S/N & Items & Frequency & Percentage \\
\hline 1 & Research bias & 24 & $25 \%$ \\
\hline 2. & Issue of sponsorship & 9 & $9 \%$ \\
\hline 3 & $\begin{array}{l}\text { Suitability of questionnaires (as an instrument) to the } \\
\text { research design chosen for a study }\end{array}$ & 11 & $12 \%$ \\
\hline 4 & Respondent's ability to interpret the items or questions & 34 & $35 \%$ \\
\hline 5 & $\begin{array}{l}\text { The time lapse in the administration and collection of the } \\
\text { questionnaire }\end{array}$ & 13 & $14 \%$ \\
\hline 6 & Unforeseen circumstances & 5 & $5 \%$ \\
\hline
\end{tabular}

In constructing questionnaires, the respondents indicated that they fear and consider the following; research bias indicated by $24(25 \%)$ of the respondents, issue of sponsorship indicated by $9(9 \%)$ of the respondents, suitability of the questionnaire (as an instrument) to the research design chosen for the study indicated by $11(12 \%)$ of the respondents, respondents' ability to interpret the items or questions as indicated by $34(34 \%)$ of the respondents, time lapse in the administration of the questionnaire as indicated by13(14\%) of the respondents and unforeseen circumstances indicated by $5(6 \%)$ of the respondents.

Table 4:- General opinion on the questionnaire as an instrument for data collection in LIS researches Response.

\begin{tabular}{|l|l|l|l|}
\hline S/N & Items & Frequency & Percentage \\
\hline $\mathbf{1 .}$ & $\begin{array}{l}\text { The questionnaire is a preferred instrument for data } \\
\text { collection in most LIS researches }\end{array}$ & $71 \%$ \\
\hline $\mathbf{2}$ & $\begin{array}{l}\text { The questionnaire is disadvantageous than other } \\
\text { instruments like interview in data collection }\end{array}$ & 28 & $29 \%$ \\
\hline
\end{tabular}

In the general opinion of the respondents on how the question is viewed and seen, $68(71 \%)$ of the total respondent accepted questionnaire as a preferred instrument for data collection because of its advantages which include;- easy to analyze and cost effective when compared with face to face interview and others, responses are gathered in a standardized way, it is relatively quick to collect information; questions in the questionnaire are usually presented in a good logical order from general to more specific response and it is attractive in appearance, neatly arranged and clearly printed. 
The remaining 28(29\%) of the respondents who disagreed rather saw some disadvantages with the use of questionnaire. Such disadvantages as a lot of apathy as shown towards the acceptance and filling of questionnaire, researchers often design and distribute questionnaire which were never attended to, they may get lost in transit especially when they are many, the cost of production is always high especially with a large population which runs in thousands. Finally they noted that responses are not given attention especially if the questions are ambiguous and biased. These and other related reasons were given by the respondents as weaknesses of the questionnaire.

The respondents when asked what they considered using the questionnaire as a research instrument, mentioned the following; educational level or academic status, topic to be treated, type of questions to be asked and type of research to be carried out as determinants of their choices.

Table 5:- General Constraints to research and publishing.

\begin{tabular}{|l|l|l|l|}
\hline No & Constraints to publishing & Frequency & Percentage \\
\hline 1. & Lack of interest in publishing & 18 & $19 \%$ \\
\hline 2. & Does not contribute to my promotion & 24 & $25 \%$ \\
\hline 3. & Finds it difficult to write research reports & 32 & $33 \%$ \\
\hline 4. & Non-acceptance of written articles for publication & 22 & $23 \%$ \\
\hline & Total & $\mathbf{9 6}$ & $\mathbf{1 0 0 \%}$ \\
\hline
\end{tabular}

In table 5 above on constraints to research and publishing, the response rate were as follows-: $32(33 \%)$ indicates that they find it difficult to write research, 24(25\%) indicated it does not count for their promotion, 22(23\%) indicated non-acceptance of written articles for publication while 18(19\%) indicated lack of interest in publishing.

\section{Discussion of findings:-}

The ultimate goal of research work is to see that data are collected, collated and analyzed. The ability of the researchers to collect and analyze data effectively to a great extent contributes to the success of the research. To show the importance of a research instrument on the collection of data, Aina (2004) noted that the research instrument provide a general framework for the collection of appropriate data. That is why the questionnaire as one of the reliable instruments for data collection was highly accepted as indicated by the respondents despite its lapses. A variety of questions are asked within the questionnaire to help elicit the necessary data required for a study. This conforms to the assertions of Key (1997), Brown (2001) and subsequently Nkwocha (2007) that the questionnaire presents respondents with a series of questions or statements to which they are to react either by writing out their answers or selecting from amongst existing answers. Onyango (2002) specifically pointed out the different types of questions which could be presented in a questionnaire to include factual questions, attitude and perception questions, standard-of-actions questions amongst others.

Results further showed that factors like suitability of the questionnaire to the research design, time lapse for the response amongst others are considered during questionnaire construction. This is in line with what High Education Academy (2009) which stated that questionnaires whether open or closed must consider these points; clarity, leading questions, phrasing, embracing, embarrassing questions, hypothetical questions, prestige, bias etc. Most of the respondents saw the questionnaire as a reliable instrument for data collection as against few who were against its use. This revealed a great preference for its use, despite its short falls as was earlier harnessed by Key (1997) and Higher Education Academy (2010). However, some constraints were found to hinder research and publishing generally and particularly in the area of library and information science. Such constraints as difficulty in writing research reports, frequent rejection of articles by notable journals, little impact made by publications on promotion, and least of all, lack of interest in research and publication.

\section{Implications of the study:-}

The findings of the study having revealed the strengths and weaknesses of the questionnaire as an instrument for data collection have far reaching implications for researchers in different fields not just in LIS alone. Studies are being carried out for the advancement of the various human disciplines and researchers need to know more about the instruments for data collection of which the questionnaire is one of the commonest. Researchers from the findings of this study will know how suitable or not the questionnaire as an instrument can be for the collection of their required data. 


\section{Conclusion:-}

The use of questionnaire in research for collecting data cannot be contested. As a mechanism for obtaining information and opinions, the questionnaire has a number of advantages and disadvantages when compared with other evaluation tools. The questionnaire, despite its weaknesses, stands the test of time as a reliable instrument for data collection for its numerous advantages. It permits respondents time to consider their response carefully without interference for the research. It helps to address a number of issues (amongst others) at a given time which is rare in other methods.

In conclusion therefore, the questionnaire as a reliable instrument for data collection should be adequately monitored in order to curtail its weaknesses to a great extent when it is being used in research. A researcher should make frank effort to see that what researchers claim to do with questionnaires is actually done with good supervision and monitoring. Empirical studies carried out with the questionnaire should be relied on and their recommendations be taken seriously. People should try to develop positive attitude towards accepting and filling of questionnaire for credibility, reliability and usability of the research results. The government should encourage researchers by group research grants to enable them carry out researches. Where researchers are bound to carry out these researches without financial assistance, the tendency for manipulating figures and falsification will not be ruled out. Good counseling and awareness will go a long way to enhance the use and response to questionnaires and that will create a better study atmosphere and yield better results.

\section{Recommendations:-}

The following recommendations are made based on the findings of the study:-

1. The use of questionnaire for data collection should be effectively monitored so as to reduce to a great extent its short-comings.

2. Critical analysis of questionnaire and the recommendations made should be used to address new and further occurrences.

\section{References:-}

1. Aino, L. O. (2002). Introduction to research. In L.O. Aino (Ed). Research in information science: an African Ibadan: Striling-Horden Publishers (Nig.) Ltd.

2. Aino, L. O. (2004). Library and information sciences text for Africa. Ibadan: Third world information service

3. Limited.

4. Best, J. W. and Kahn, J. V. (1998). Research in education Boston: Allyn and Bacon.

5. Brown, J. D. (2001). Using Surveys in Language Programs. Cambridge: Cambridge University

6. Press.

7. Dornyei, Z (2007). Research Methods in Applied Linguistics: Quantitative, Qualitative and Mixed Methodologies. 1st Edition. Oxford: Oxford University Press.

8. Higher Education Academy (2010). Economics Network. Retrieved from file //E:/al\%20questionnaire/1$38 \%, 20$ what $\% 20 \%$ valid on $11 / 2 / 13$.

9. Key, J.P. (1997). Qualitative research design in occupational education. Okhaloma: Okhaloma State University.

10. Leedy, P. D. (1993). Practical research planning and design $3^{\text {rd }}$ ed. New York Macmillan Publishing Company.

11. Nkwocha, P. C. (2009). Educational research process made easy. Onern: Chinasa-Hop Publishers.

12. Obodoeze, F. O. (1996). Modern textbook of research methodology. Enugu Academic Publishing Company.

13. Onyango, R. A. O. (2002). Data collection instrument in information science. In L.O. Aino (Ed) Research in information science: an African perspective. Ibadan: Stirling-Horden Publishers (Nig.) Ltd.

14. Oppenheim, A. N. (1992). Questionnaire Design, Interviewing and Attitude Measurement. London: Pinter Publishers Limited.

15. Osuala, E. C. (2005). Introduction to research methodology, $3^{\text {rd }}$ ed. Onitsha: Africana-First Publishers Limited. 